\title{
Drosophila morgue influences cell numbers and positions in the embryonic nervous system
}

\author{
BARBARA A. SCHREADER, YIQIN WANG, STEPHANIE CARTER, JOANNA GRIGAS and JOHN R. NAMBU* \\ Biology Department, University of Massachusetts, Amherst MA, USA
}

\begin{abstract}
Morgue is a unique multi-domain protein that contains a zinc finger motif, an $\mathrm{F}$ box, and a variant E2 conjugase domain. The presence of these domains suggests potentially complex and novel functions for Morgue in ubiquitination pathways. Morgue was originally identified via its gain-of-function enhancement of eye cell death phenotypes in Drosophila and ectopic expression of Morgue also influences circadian rhythms. However, there is as yet little known about Morgue's normal developmental or physiological functions. To address this issue, we generated several morgue loss-of-function mutants via $P$ element excision mutagenesis and analyzed the mutant phenotypes during the fly life cycle. These studies revealed that morgue null mutants are viable, though approximately $10 \%$ of the mutants exhibit defects in pupal spiracle eversion and malformations in the adult abdominal cuticle. In addition, a similar subset of morgue mutant embryos exhibited alterations in the normal number, position, or morphology of specific neurons and glia. Analysis of Morgue protein localization was addressed through generation of a transgenic fly strain that expresses a GFP::Morgue fusion protein. Use of this strain revealed Morgue protein localization in multiple cellular compartments, including nuclei, cytoplasm and membranes. Taken together, these diverse phenotypes and distribution patterns suggest pleiotropic functions for Morgue.
\end{abstract}

KEY WORDS: Drosophila, morgue, cell death, ubiquitin, nervous system

\section{Introduction}

Protein ubiquitination is a highly conserved and tightly regulated post-translational modification that is mediated by an enzymatic cascade where the sequential functions of an $E 1$ activator, E2 conjugase, and E3 ligase transfer ubiquitin onto specific substrate proteins (Pickart and Eddins, 2004; Ciechanover 2005). Formation of a poly-ubiquitin chain targets a substrate to the $26 \mathrm{~S}$ proteasome complex that can degrade or process the protein while mono-ubiquitination can result in endocytic engulfment. Ubiquitination can influence protein stability, activity, or localization and is critical in a wide array of developmental and physiological processes. In addition, several human pathologies are associated with abnormal accumulations of ubiquitinated proteins. Ubiquitination plays a crucial role in cell survival decisions by regulating the relative levels of antagonistic death activators and death inhibitors (Lee and Peter 2003). Significantly, members of the Inhibitor-of-Apoptosis (IAP) protein family contain both caspase-binding BIR domains and an E3 ubiquitin ligase RING domain and can repress apoptosis by preventing the activation or function of bound caspases as well as promoting their ubiquitination and proteasome-mediated turnover (Vaux and Silke 2005; Steller, 2008). In Drosophila, IAPs are essential for cell survival; loss-offunction diap1 mutants exhibit embryonic lethality and massive ectopic cell death, and cell lethal effects of diap1 loss is observed in somatic tissues (Hay 2000). In mammals, IAPs are also important for cell survival and mis-regulation of IAP expression is associated with the immortality of transformed oncogenic cells (Wright and Duckett 2005). In both flies and mammals, IAP activities are strongly influenced by a set of related antagonists. In Drosophila, this includes 4 related RHG proteins, Reaper,

\footnotetext{
Abbreviations used in this paper: BIR, Baculovirus IAP Repeat; Cys, cysteine; DBD, dorsal bipolar dendritic; EST, expressed sequence tag; GFP, Green Fluorescent Protein; Gly, glycine; hid, head involution defective; His, histidine; HRP, horseradish peroxidase; IAP, Inhibitor of Apoptosis Protein; Lys, lysine; Morgue, Modifier of reaper and grim ubiquitously expressed; PBS, phosphate buffered saline; PG3, peripheral glial cell 3; RHG, reaper, hid, grim; RING, Really Interesting New Gene; s.d., standard deviation; UTR, untranslated region.
} 
Grim, Sickle, and Hid, that can each antagonize IAP-caspase interactions by competing with caspases for binding to the IAP BIR domain (Bergmann et al. 2003; Kornbluth and White 2005). In mammals, the related Smac/Diablo and HtrA2/Omi proteins similarly bind IAP BIR domains and repress caspase neutralization (Vaux and Silke 2003). These observations suggested a double-repression model of cell death, whereby death-inducing caspase actions are normally held in check by the IAPs. This inhibition is removed by expression of IAP antagonists, which are either transcriptionally regulated (e.g. Drosophila reaper) or selectively released from the mitochondria (e.g. mammalian Smac/ Diablo and HtrA2/Omi) in response to pro-death stimuli. Importantly, IAP antagonists can induce IAP auto-ubiquitination and proteasome-dependent degradation to facilitate apoptosis (Ryoo et al. 2002; Yoo et al. 2002; Fu et al. 2003; Yang et al. 2004). In addition, IAPs can ubiquitinate and promote degradation of their antagonists (MacFarlane et al. 2002; Olson et al. 2003; Wilkinson et al., 2004). Thus, the regulation of IAP levels and ubiquitination activities is under complex proteolytic control that is crucial for appropriate cell survival decisions.

In addition to IAPs, several other ubiquitination proteins also influence cell survival decisions and may modulate IAP functions. These include both well-defined types of ubiquitination proteins, such as the E2 conjugase UbcD1/Effete (Ryoo et al. 2002; Yoo et al. 2005), as well as several novel ubiquitination proteins including Scythe (Thress et al. 1998; Desmots et al., 2005), Bruce (Hauser et al., 1998; Bartke et al. 2004), and Morgue (Hays et al. 2002; Wing et al., 2002). To help clarify functional interactions between the ubiquitin/proteasome pathway and programmed cell death, we have focused attention on the Drosophila morgue gene. Morgue was initially identified in genetic modifier screens based on the eye cell death induced by targeted R/Grim gene expression or mutations in the irreC-roughest gene (Hays et al., 2002; Wing et al. 2002). A function for morgue in cell death pathways was further implied by demonstration that morgue $\mathrm{P}$ element insertion alleles or a morgue deletion mutant dominantly suppressed RHG (Reaper, Hid, Grim)-mediated eye cell death and exhibited ectopic lattice cells in the developing ommatidia. Furthermore, Morgue expression induced apoptosis in cultured insect cells and downregulated DIAP1 levels; Morgue was also shown to directly associate with DIAP1 and downregulate DIAP1 levels (Hays et al. 2002; Wing et al., 2002). In addition to its role in programmed cell death, Morgue has also been implicated in circadian rhythms pathways as targeted Morgue expression rescues behavioral arrhythmicity exhibited by flies reared in conditions of constant light (Murad et al. 2007). Consistent with potentially diverse functions, the morgue gene exhibits widespread expression throughout the fly life cycle.

Significantly, the 491 amino acid Morgue protein contains a unique combination of functional domains. This includes an $\mathrm{NH}_{2}-$ terminal $\mathrm{CX}_{2} \mathrm{CX}_{8} \mathrm{CX}_{2} \mathrm{C}$ zinc finger motif, a centrally-located $\mathrm{F}$ box that includes five stereotypic Tryptophan residues, and a $\mathrm{COOH}$ terminal variant E2 conjugase domain where the active site Cysteine is replaced by a Glycine residue. The putative Cys4 type zinc finger is of unknown activity but is well conserved in all Morgue homologs (Zhou et al. 2009). $F$ box proteins serve as adaptors in SCF E3 ubiquitin ligase complex that bind to a Skp protein and a specific substrate protein that is targeted for ubiquitination by an E2 ubiquitin conjugase (Ho et al. 2006). Consistent with potential functions as an $\mathrm{F}$ box protein, Morgue associates with Drosophila SkpA in an F box-dependent manner (Wing et al. 2002; Giot et al. 2003) and contains potential substrate binding regions. The Morgue E2 conjugase domain shows strong sequence similarity to other E2s, including Drosophila UbcD1/Effete, which also associates with DIAP1 and promotes DIAP1 turnover (Ryoo et al. 2002). However, the Gly/Cys active site substitution implies that Morgue cannot form a covalent thioester linkage to ubiquitin and lacks the catalytic capability to directly mediate ubiquitination. Morgue may thus also/instead act as a Ubiquitin E2 Enzyme Variant (UEV). UEVs all lack the active site cysteine although some UEVs, such as MMS2 or UEV1, can associate non-covalently with ubiquitin and may form catalytically active heterodimers with another bona fide E2, such as Ubc13 (Eddins et al. 2006; Hau et al. 2006; Lewis et al. 2006). All Morgue homologs share the active site Gly/Cys substitution (Zhou et al. 2009), suggesting a specific functional requirement for Glycine in this position. Interestingly, no other known UEV contains a Glycine in the active site. This unique combination of both an E2 and E3 functional domain on one polypeptide suggests Morgue may provide novel ubiquitination activities.

Despite an apparent role for Morgue in regulating cell survival, there is as yet limited information on its normal functions in living and dying cells during development. These analyses have been hampered both by a lack of specific morgue null alleles and lack of knowledge on the subcellular sites of action for Morgue protein. In this study we address these issues. First, specific morgue lossof-function alleles were generated via $P$ element excision mutagenesis. These mutations delete portions of the Morgue coding

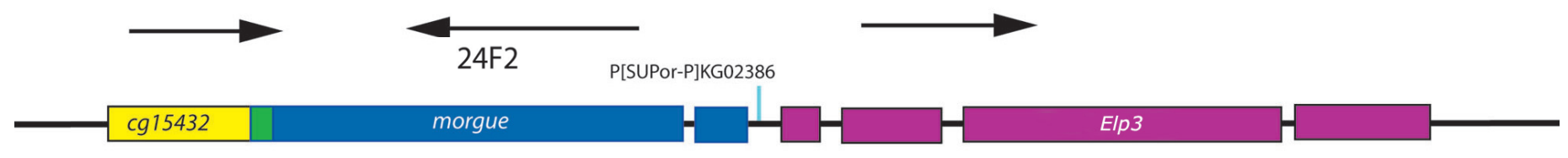

$$
\begin{aligned}
& \text { morgue }^{457} \\
& \text { morgue }^{126} \\
& \text { morgue }^{19}
\end{aligned}
$$

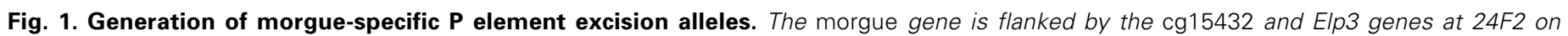

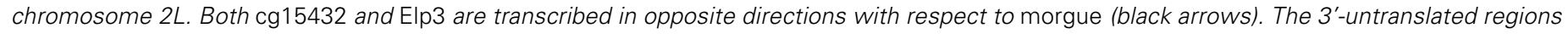

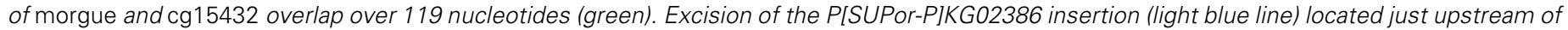

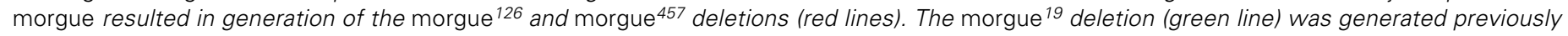
(Wing et al. 2002) and removes the entire coding region of morgue as well as a portion of cg15432. 
region but do not disrupt sequences of the nearby cg15432 or Elp3 genes. These morgue-specific deletion mutants are homozygous viable and fertile. However, some mutant animals exhibit disruptions in anterior spiracle eversion during pupariation and abnormal tergite elaboration during formation of the adult abdomen. As high levels of cell death normally occur in the developing nervous system, embryos lacking maternal and zygotic morgue function were examined using several markers that label specific sets of neurons and glia. This analysis revealed that morgue functions influence the numbers, positions, and morphologies of discrete CNS and PNS cell types. Finally, to gain insight into the distribution of Morgue protein within cells we examined the localization of GFP::Morgue and Morgue::6XHis fusion proteins. Morgue was localized in several cellular compartments in distinct cell types. Taken together, these findings suggest widespread and diverse functions for morgue in multiple developmental processes.

\section{Results}

\section{Morgue-specific mutants are viable and exhibit anatomical defects}

Previous genetic analyses of morgue function utilized either the EP2367 and EP1184 morgue P element insertions, or a small morgue deletion, morgue ${ }^{19}$ (Hays et al. 2002; Wing et al. 2002). The EP2367 and EP1184 strains are homozygous viable and respectively contain insertions of the EP P element in the 5'-UTR or 3'-UTR of morgue. Neither of these alleles corresponds to a morgue null mutation. In contrast, morgue ${ }^{19}$ is a null allele that deletes the entire protein-coding region; these mutants exhibit a fully lethal phenotype (Wing et al. 2002). However, morgue ${ }^{19}$ also deletes a portion of the nearby $\mathrm{cg} 15432$ gene (Fig. 1). Analysis of a cg15432 EST (GenBank BT032808.1) indicated that the proximal breakpoint of the morgue ${ }^{19}$ mutation extends through the 134 base pair 3'-UTR and final 12 amino acids encoded by $c g 15432$. The 118 amino acid CG15432 protein contains a lysine-rich $\mathrm{NH}_{2}-$ region and a COOH-terminal DUF1674 domain (see: http:// www.flybase.org/reports/FBgn0031603.html). CG15432 corresponds to a member of the Fam32A protein family that is very highly conserved in a wide range of invertebrate and vertebrate organisms, including C. elegans and humans (Lai et al. 2000), suggesting important, though as yet unknown functions. The morgue gene is also closely flanked on the 5' (proximal) side by the Elp3 gene that encodes a 552 amino acid protein resembling an Acyl-CoA N-acyltransferase (see: http://www.flybase.org/reports/FBgn0010235.html). To fully understand morgue function it is important to obtain morgue-specific mutations that do not disrupt $c g 15432$ or Elp3 and we therefore sought to generate morgue-specific null alleles. A P element excision screen was performed on the P[SUPor-P]KG02386 insertion located in the morgue 5'-UTR, 51 base pairs upstream of the Morgue start codon (Fig. 1). Approximately 100 excisions were analyzed for viability and subjected to PCR assays using primers in and around the morgue gene to identify and characterize deletion events. From these analyses, two morgue-specific deletions were identified, morgue ${ }^{126}$ and morgue ${ }^{457}$. The two alleles share the same 5' breakpoint that corresponds to the site of the $\mathrm{P}$ element insertion. The morgue $\mathrm{e}^{457}$ deletion extends for 595 base pairs and removes the coding region up to the Asp145 residue located between the zinc finger and $\mathrm{F}$ box (Fig. 1). The morgue ${ }^{126}$ deletion extends for 1,131 base pairs and ends at Ala321 between the $F$ box and conjugase domain (Fig. 1). Neither deletion impacts the transcribed portions of $c g 15432$ or Elp3. Both mutant alleles remove the native initiator Methionine as well as significant portions of the morgue coding region. This suggests that they act either as a strong hypomorph or null allele to greatly impair or eliminate Morgue functions. In addition to these loss-of-function morgue alleles, several precise excision alleles, including morgue ${ }^{100}$, were obtained.

Unlike morgue ${ }^{19}$, homozygous morgue ${ }^{126}$ and morgue ${ }^{457}$ mutants are viable, although the mutant flies are somewhat lethargic. Both new alleles are also viable when placed in trans to morgue ${ }^{19}$. We first analyzed the new morgue alleles for their ability to suppress the phenotype of P[GMR-hid] flies. Heterozygosity for the morgue ${ }^{126}$ or morgue ${ }^{457}$ allele resulted in a dominant suppression of ectopic eye cell death (Fig. 2A) that is comparable to that seen for the morgue ${ }^{19}$ null allele (Wing et al. 2002). The extent of suppression was not significantly enhanced by homozygosity for either the morgue ${ }^{126}$ or morgue ${ }^{457}$ mutation (data not shown). This indicates that a specific reduction of morgue function is sufficient to attenuate the death-inducing activities of RHG genes.

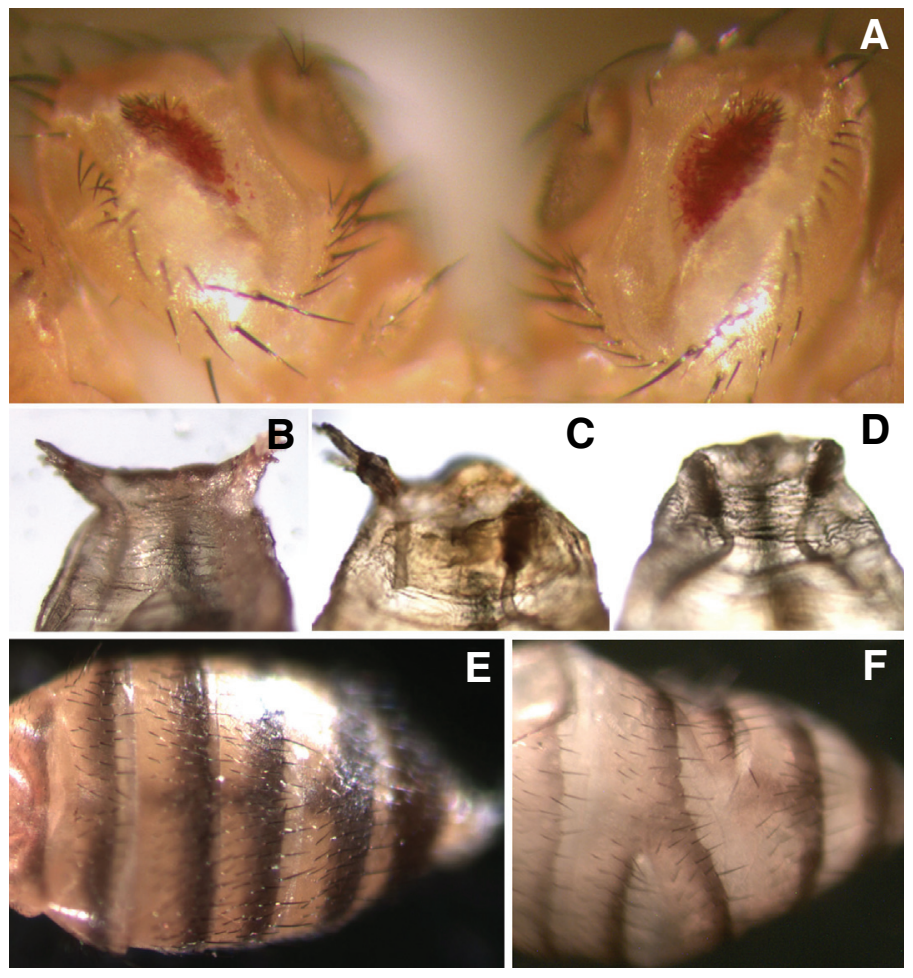

Fig. 2. Morgue mutants exhibit dominant suppression of HID-induced eye cell death and defects in pupal case and adult cuticle formation. (A) The ectopic eye cell death in P[GMR-hid]/+ flies (left) is dominantly suppressed by heterozygosity for the morgue ${ }^{126}$ allele in P[GMR-hid]/morgue ${ }^{126}$ flies (right). (B-D) In contrast to a wild type pupae (B), $13 \%$ of homozygous morgue ${ }^{457}$ mutant pupae fail to normally evert either one (C) or both (D) of the anterior spiracles. (E,F) Wild type adult flies (E) possess well-organized tergite plates on the dorsal abdomen that exhibit clear segmental reiteration. $10 \%$ of homozygous morgue ${ }^{126}$ adults exhibit disruptions in the normal elaboration of tergites that include misalignment and aberrant segmental organization (F). 
A subset of morgue ${ }^{126}$ and morgue 457 mutants exhibited anatomical abnormalities in the pupal and adult stages. Specifically, in the pupal cases of $10.0 \%(51 / 511)$ of morgue $^{126}$ mutants and $13.0 \%(68 / 523)$ of morgue 457 mutants, one or both of the anterior spiracles failed to evert and extend (Fig. 2 B-D). While these defects were incompletely penetrant, no such eversion defects were observed in wild type $(n=530)$ or morgue ${ }^{100}$ pupae $(n=498)$. Furthermore, $10.2 \%$ of both eclosed morgue ${ }^{126}(52 / 507)$ and morgue 457 (50/488) adult flies exhibited malformations in the tergite plates on the dorsal abdomen (Fig. 2 E,F). These disruptions varied in severity and included disruptions, fusions, or
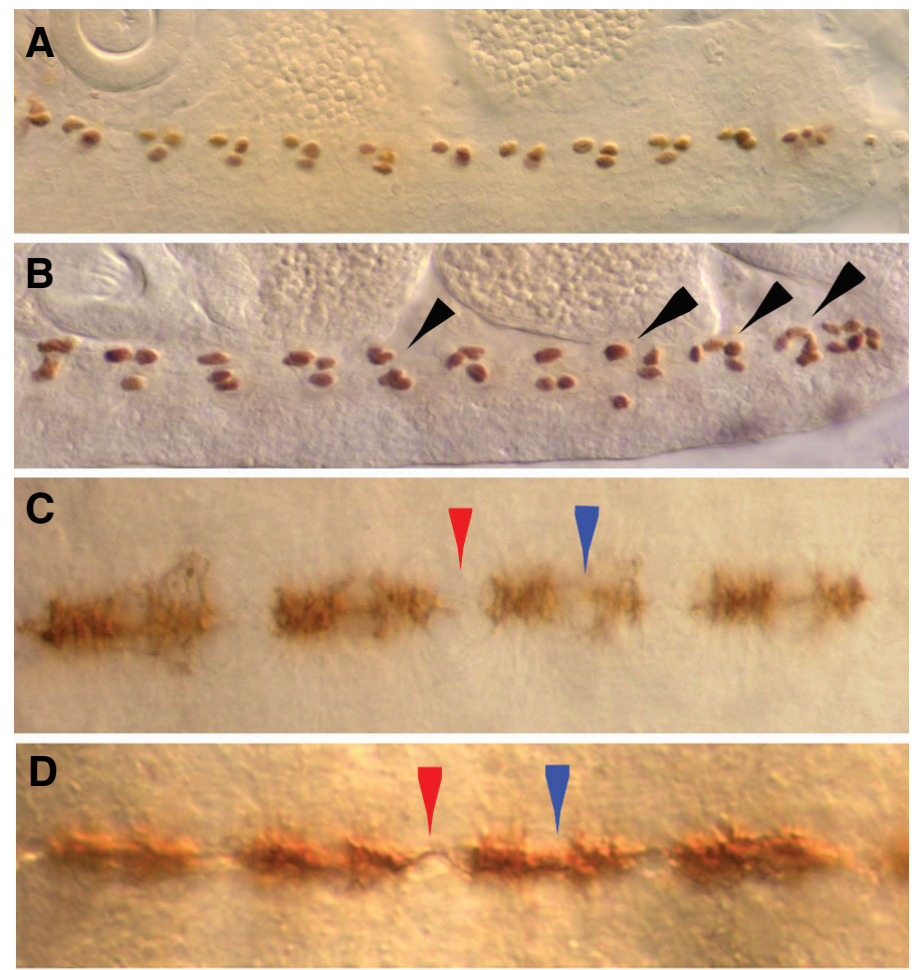

E

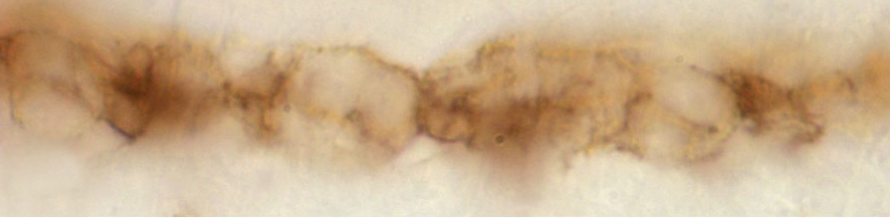

Fig. 3. Morgue mutant embryos exhibit altered numbers and morphology of embryonic CNS midline glia. (A,B) Anti- $\beta$-galactosidase immunostaining labels the nuclei of CNS midline glia in stage 16 wild type (A) and morgue ${ }^{126}$ mutant (B) embryos carrying a P[1.0slit-lacZ] marker. Note that several ganglia of morgue mutant embryos contain ectopic and misplaced midline glia (arrowheads). (C-E) Anti-Wrapper immunostaining labels the membranes of CNS midline glia. Note that in stage 16 wild type embryos (C) there is clear separation between the anterior and posterior midline glia in each ganglion (red arrowhead) as well as the glia of each ganglion (blue arrowhead). This separation is disrupted in morgue ${ }^{126}$ mutant embryos (D) as glial processes extend aberrantly across (red arrowhead) and within (blue arrowhead) ganglia. In Df(3L)H99 mutant embryos where all midline glial death is blocked, there is a more pronounced disorganization and distortion of these glial processes (E). $(A, B)$ sagittal view; $(C-E)$ ventral view. truncations, along the midline of the tergites. These defects were also not observed in wild type $(n=559)$ or morgue ${ }^{100}(n=474)$ flies. No other anatomical defects were detected in morgue mutant animals.

\section{Morgue mutant embryos exhibit altered numbers, morphol- ogy, or positions of specific neurons and glia}

Development of the nervous system requires elaboration of a precise and stereotyped pattern of neurons and glia. This pattern is in part determined by controlled removal of excess or inappropriate cells via programmed cell death. To further characterize the developmental functions of morgue, we employed several markers to analyze the differentiation and survival of specific neurons and glia in morgue mutants. Significantly, embryos derived from homozygous morgue ${ }^{457}$ and morgue ${ }^{126}$ mutants were lacking both maternal and zygotic functions of morgue.

The CNS midline glia undergo prominent cell death during germ band retraction which decreases their numbers from 9 to 3 per ganglion (Sonnenfeld and Jacobs, 1995; Zhou et al., 1995). To determine if midline glial deaths are altered in morgue mutants, a P[1.0slit-lacZ] marker was crossed into morgue mutant backgrounds and the progeny embryos were analyzed via anti- $\beta$ galactosidase immunostaining. In stage 16 morgue mutant embryos 1-2 additional midline glia were detected in several, though not all ventral nerve cord ganglia (Fig. $3 A, B)$. This implies that in the absence of morgue the normal level of midline glial cell death was decreased. In addition, anti-Wrapper immunostaining revealed altered morphology along the midline of morgue mutants. Compared to wild type embryos, morgue $e^{126}$ and morgue $e^{457} \mathrm{mu}$ tants exhibited aberrant midline glial cytoplasmic processes that were not well separated and often extended across inter-ganglia borders (Fig. 3 C,D). Interestingly, a similar, though more severe, disruption of midline glial processes was observed in $\mathrm{Df}(3 \mathrm{~L}) \mathrm{H} 99$ mutant embryos which contain a three-fold excess of midline glia (White et al. 1994) (Fig. 3E).

The role for morgue in cell survival was further analyzed by examining the survival of larval photoreceptor neurons, another cell lineage that undergoes prominent programmed cell death during embryogenesis. In stage 16 wild type embryos these Krüppel-expressing neurons reside in two symmetric clusters of 9 cells each in the dorsal cephalic region while in $\mathrm{Df}(3 \mathrm{~L}) \mathrm{H} 99$ mutants where cell death is blocked, there are 17 neurons per cluster (Grether et al. 1995). Anti-Krüppel immunostaining revealed that in morgue mutants the average number of these neurons was unaltered; however compared to wild type embryos there is greatly increased variability in the number of neurons per cluster (average: 8.86 s.d. 1.94 per cluster for the wild type [ $n=63$ clusters] and 8.94 s.d. 5.74 for morgue ${ }^{126}$ mutants [n=65 clusters]). The morgue mutant embryos exhibited a much greater range of Krüppel-expressing neurons per cluster (Fig. 4 A-D). In addition, unlike wild type or $\mathrm{Df}(3 \mathrm{~L}) \mathrm{H} 99$ mutants, individual morgue mutant embryos also displayed substantial asymmetry in the number of neurons within each of the two clusters.

The defects in cellular number and morphology in morgue mutants prompted us to examine whether morgue might also influence cell positions within the embryonic nervous system. This was addressed using Anti-Repo immunostaining to analyze peripheral glial cells which migrate large distances during germ band retraction from the dorsal neuroectoderm to dorsal/lateral 

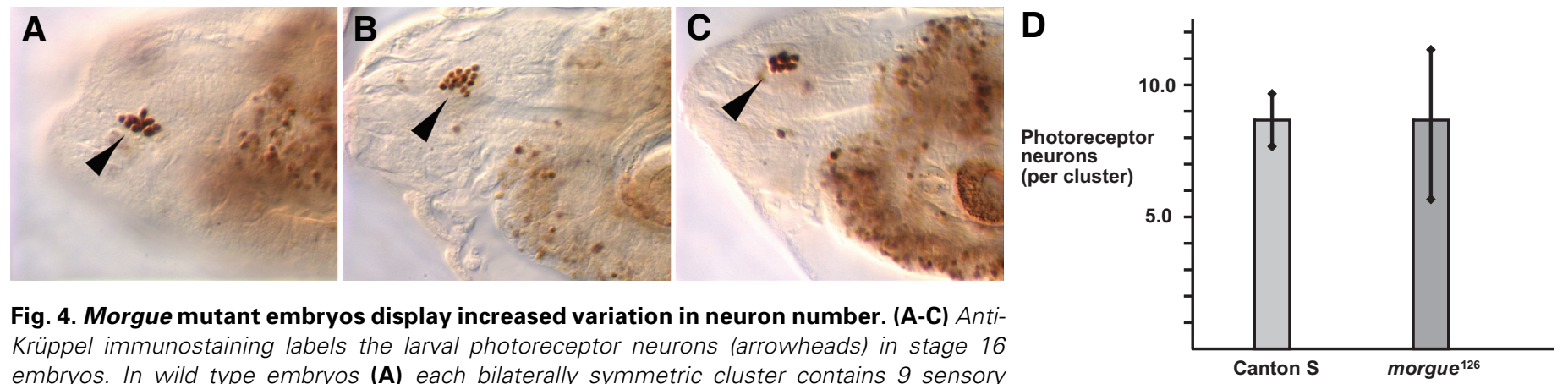

Fig. 4. Morgue mutant embryos display increased variation in neuron number. (A-C) AntiKrüppel immunostaining labels the larval photoreceptor neurons (arrowheads) in stage 16 embryos. In wild type embryos (A) each bilaterally symmetric cluster contains 9 sensory neurons. morgue mutants exhibit greatly increased variability in the number of these photore-

ceptor neurons as evidenced by the presence of 14 (B) or 6 (C) neurons in a morgue ${ }^{126}$ mutant embryo. All views are sagittal with anterior to left. (D) Plot of the average number of Krüppel-expressing larval photoreceptor neurons present in clusters from stage 16 wild type (light grey; $n=63$ ) and morgue ${ }^{126}$ mutant (dark grey; $n=65$ ) embryos. The standard deviations are indicated by tipped vertical lines. Note that there is greatly increased variation in neuron numbers observed in the morgue mutants.

positions in the embryo (Sepp et al. 2000). In stage 16 morgue mutants, altered positions observed for the nuclear positions of both the DBD support glia and PG3 glia. In wild type embryos, these cells are found in an inverted L-shaped configuration where the nucleus of the DBD glia is arrayed horizontally and lies just dorsal and posterior to the nucleus of the PG3 glia which is arrayed vertically (Fig. 5A; Umesono et al. 2002). However, in several segments of each morgue mutant embryo the DBD and PG3 nuclei were mis-positioned, with the DBD nucleus often located anterior or dorsal to the PG3 nucleus (Fig. 5B). These defects also exhibited variable severity both between individual embryos and within different segments of a single embryo. Interestingly, similar, though more severe disruptions were observed in $\mathrm{Df}(3 \mathrm{~L}) \mathrm{H} 99$ mutant embryos where the PG3 and DBD glia were often duplicated as well as mis-positioned (data not shown).

\section{A GFP::Morgue fusion protein exhibits widespread localiza- tion}

The Morgue protein does not contain any identifiable domain or motif that implies a specific site of subcellular localization. To identify the potential subcellular sites of Morgue action we generated a P[UAS-GFP::Morgue] fly strain. Targeted expression of GFP::Morgue exhibited comparable enhancement of R/Griminduced eye cell death as full length native Morgue (Wing et al. 2002 and data not shown), suggesting that it has similar biological activity. In addition, both native Morgue and GFP::Morgue also induced lethal phenotypes when expressed at high levels via a distinct P[Gal4] driver (Y. Zhou and J.R.N. in preparation). Expression of GFP::Morgue was targeted to the larval salivary glands using the P[SaGa52A-Gal4] driver strain (Mukherjee et al. 2000). These glands contain large cells with easily distinguished nuclei and cytoplasm. In third instar P[SaGa52A-Gal4]/P[UASGFP::Morgue] larvae, GFP::Morgue exhibited widespread localization within salivary gland cells where it was detected in the nucleus and cytoplasm as well as along the plasma membrane (Fig. 6A). To determine if similar distribution is observed in other cell types, a P[repo-Gal4] line was used to target GFP::Morgue expression in glial cells. Analysis of the central nervous system of third instar larvae revealed GFP::Morgue localization in glial nuclei and cytoplasmic processes (Fig. 6B). Morgue protein distribution was further investigated via expression of a Morgue-
6xHis protein in cultured insect Sf9 cells. Anti-His immunostaining revealed prominent localization of Morgue-6xHis protein in the cytoplasm and weaker distribution in the nuclei of transfected cells (Fig. 6C). Thus, the tagged Morgue proteins localize in multiple cellular compartments in distinct cell types.

\section{Discussion}

\section{Generation of morgue-specific mutants}

Initial genetic studies of morgue function revealed that a small deletion allele, morgue ${ }^{19}$, exhibits recessive lethality and dominantly suppresses the cell death induced by ectopic Reaper or Hid expression (Wing et al. 2002). However, interpretation of loss-offunction morgue phenotypes based on morgue ${ }^{19}$ is complicated by simultaneous disruption of the adjacent $\operatorname{cg} 15432$ gene. Significantly, the morgue ${ }^{19}$ mutant deletes the entire 3'-UTR and last 12
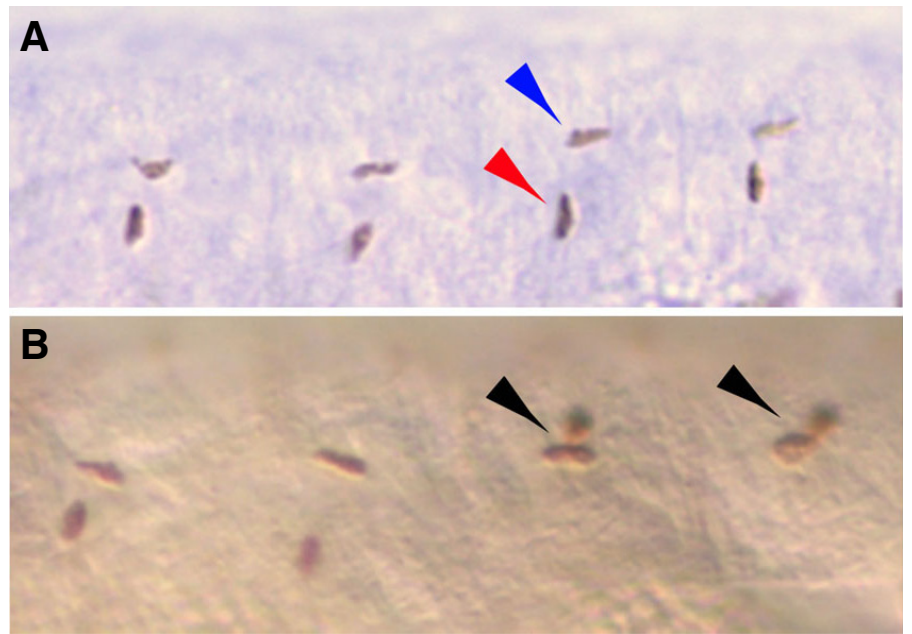

Fig. 5. Morgue mutants exhibit mis-positioning of embryonic peripheral glial. (A,B) Anti-Repo immunostaining labels the nuclei of peripheral glial cells. Note that in stage 16 wild type (A) embryos the nucleus of the DBD glia (blue arrowhead) resides dorsal and slightly posterior to the nucleus of the PG3 glia (red arrowhead). In stage 16 morgue mutant embryos (B) the positions and shapes of these glial nuclei are altered (arrowheads) and the PG3 nucleus often resides directly dorsal to the DBD nucleus. Sagittal views with anterior to left. 

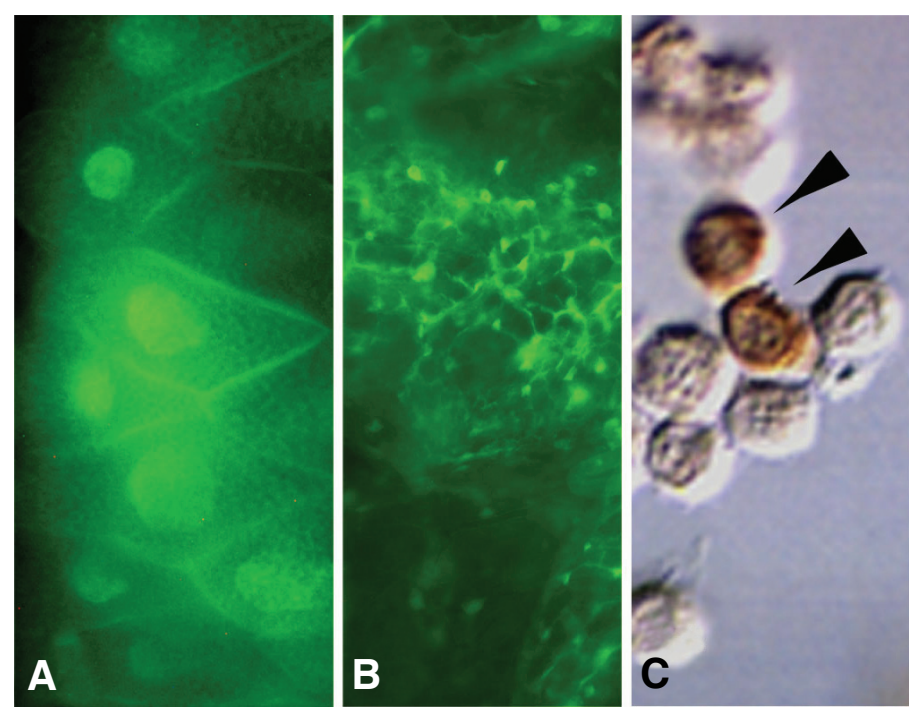

Fig. 6. The MORGUE protein exhibits diverse localization within Drosophila cells. (A) The P[SaGa52A-Gal4] driver strain was used to target expression of GFP::Morgue proteins in third instar larval salivary glands. Note widespread distribution of GFP::Morgue in membrane, cytoplasmic, and nuclear compartments. (B) Targeted expression of GFP::Morgue via P[repo-Gal4] reveals distribution of GFP::Morgue in the in third instar larval CNS glial nuclei, cytoplasm, and processes. (C) Detection of a 6xHis-Morgue protein in cultured insect Sf9 cells via antiHis immunostaining reveals cytoplasmic and nuclear localization of 6xHis-Morgue in transfected cells (arrowheads).

amino acids of the $\operatorname{cg} 15432$ coding region. $\operatorname{cg} 15432$ encodes a DUF1674 domain protein that has a lysine-rich $\mathrm{NH}_{2}$-region and is a member of the FAM32A protein family. This protein is highly conserved in a wide range of organisms, suggesting important, albeit as yet undetermined functions. We therefore sought to obtain morgue-specific mutants to facilitate analysis of Morgue functions. In this study we describe two small morgue deletion mutations that remove portions of the morgue coding region but do not extend into $c g 15432$. Like morgue ${ }^{19}$, the morgue-specific alleles also exhibit dominant suppression of Hid-mediated eye cell death, implying that disruption of morgue alone is sufficient to modify the actions of grim-reaper genes. However, unlike morgue ${ }^{19}$, these new morgue alleles are viable. This viability suggests two interpretations for the basis of the lethality of morgue $^{19}$. Either $\operatorname{cg} 15432$ is required for viability and it is the loss of this gene that results in lethality of the morgue ${ }^{19}$ allele, or it is the combined loss of $c g 15432$ and morgue that results in the morgue $^{19}$ lethal phenotype. While full resolution of this issue awaits analysis of $c g 15432$-specific mutants, RNAi experiments suggest that the $C$. elegans homolog K01G5.8, is not an essential gene

(http://www.wormbase.org/db/gene/ gene? name=WBGene00010479). The close proximity of morgue and $c g 15432$ in other Drosophila species suggests that the two genes may share common gene regulatory elements and function in similar pathways, however, the genes are not adjacent in other insects, including the mosquito Anopheles gambiae (Schreader and Nambu, 2003), the silkmoth Bombyx morii, the honey bee Apis melifera, and the red flour beetle Tribolium castaneum (data not shown).

\section{Developmental functions of morgue}

The isolation of morgue-specific loss-of-function mutants facilitated the examination of morgue function during development. Within the developing embryonic nervous system, we analyzed the CNS midline glia and larval photoreceptor neurons, two lineages that undergo prominent developmental cell death. morgue mutant embryos exhibited ectopic mildine glia in several ganglia. This finding indicates that morgue function is not absolutely required for midline glia to die, but it is important for normal patterns of death. In the larval photoreceptor neuron lineage, there was a much greater variability and asymmetry in the number of neurons in the two clusters. This phenotype suggests that morgue influences the precision of cell survival patterns, and that in its absence, the patterns become more stochastic. The modest embryonic phenotypes of morgue mutants are similar to those for mutations in other cell death regulators, including reaper(Pedersen et al. 2000), dbruce (Vernooy et al. 2002) and bcl-2 family members (Sevrioukov et al. 2007). As Morgue clearly enhances the cell killing actions of Grim-Reaper proteins (Wing et al. 2002), its major role may be to sensitize cells to other pro-death stimuli. Morgue could also have partially redundant functions with other death regulators or be essential for death in a very specific set of cells.

The midline glia exhibited aberrant cytoplasmic extensions in morgue mutants and the peripheral glia often failed to exhibit normal localization. Aberrant cytoplasmic processes of morgue mutant midline glia could result from the presence of ectopic glia and/or altered morphology of normally surviving glia. Similar, though more severe midline defects are observed in $\mathrm{Df}(3 \mathrm{~L}) \mathrm{H} 99$ mutants, where all midline glial cell death is blocked. The defects in peripheral glial location could indicate disruption in normal cell migration or differentiation. Overall, these phenotypes suggest that Morgue could also influence cellular processes distinct from apoptosis. In this regard DIAPs and caspases function in a wide range of non-cell death processes, including the innate immune response (Stoven et al. 2003; Gesellchen et al. 2005; Kleino et al., 2005; Leulier et al. 2006; Huh et al. 2007), actin cytoskeleton dynamics (Oshima et al. 2006), spermatid individualization (Arama et al. 2003; Huh et al. 2004a; Vernooy et al. 2004), and germ cell migration (Geisbrecht and Montell 2004). In addition, dying cells can activate a caspase-dependent signaling pathway to induce neighboring cells to proliferate (Ryoo et al. 2004; Huh et al. 2004b; Perez-Garijo et al. 2004; Kondo et al. 2006). In these processes caspase activities are modulated in such a manner that they do not result in cell death. Perhaps Morgue is involved in this modulation. Morgue may also function in other physiological pathways, such as those controlling circadian rhythmicity (Murad et al. 2007). Tightly regulated ubiquitination and protein turnover are also critical for the molecular oscillations that underlie biological clocks (Chiu et al. 2008) and given its similarity to both E2 and E3 ubiquitination enzymes, it will be of interest to determine if Morgue may have similar or distinct biochemical actions in cell death and circadian rhythm processes.

\section{Morgue may function in multiple cellular compartments}

Ubiquitination proteins can exhibit diverse sites of action that permit access to disparate types of substrate proteins (e.g. Hamilton et al. 2001; Deng and Hochstrasser, 2006). We utilized GFP::Morgue and Morgue-6xHis proteins to investigate the sub- 
cellular distribution of Morgue. These proteins exhibited diverse subcellular localization that suggested Morgue could potentially function in the nucleus, cytoplasm, and cell membrane. Interestingly, Morgue does not contain a recognizable nuclear localization signal or any other domain that would suggest specific targeting properties. Therefore, Morgue distribution may be largely governed by the proteins with which it interacts. Thus, Morgue could be delivered into nuclei via interactions with nuclear proteins such as the Histone $\mathrm{H} 4$ replacement His4r or the ubiquitin specific protease Ubp64E (Giot et al. 2003). Overall, the localization of Morgue in diverse cellular compartments suggests that it may impact a wide range of ubiquitination events and substrate proteins.

\section{Materials and Methods}

\section{Generation and analysis of morgue mutants}

A P element excision screen was performed using the P[SUPorP]KG02386 strain. Deletion events were identified by PCR using morgue gene primers and genomic DNA from homozygous excision mutant adults. PCR products from the morgue excision alleles were isolated and gel purified using QIAquick Gel Extraction Kit (Qiagen, Valencia, CA) and subjected to DNA sequence analysis (Davis Sequencing, Davis CA) to determine the breakpoint sites.

Drosophila genomic DNA was isolated as described previously (Wing et al., 2002) from morgue excision mutants and analyzed via PCR using sets of primers that correspond to sites within and flanking the morgue gene. The resulting $P C R$ products were analyzed via agarose gel electrophoresis, purified via QIAGEN (Valencia CA) Qiaquick Gel Extraction kit, and subjected to DNA sequence analysis (Davis Sequencing, Davis CA) to map the excision mutations.

\section{Immunocytochemistry}

Whole mount embryo immunostaining was performed as described by Patel (1994) using the following primary antibodies: Anti-Repo (Developmental Studies Hybridoma Bank, University of lowa, lowa; 1:3 dilution), 22C10 (Developmental Studies Hybridoma Bank, University of lowa, lowa; 1:3 dilution), anti-Wrapper (gift of J.N. Noordermeer; 1:3 dilution), anti-Kruppel (gift of J. Reinitz; $1: 800$ dilution), and anti- $\beta$-galactosidase (Promega Corp., Madison WI; 1:1000 dilution). Biotinylated anti-mouse (1:200 dilution) and anti-rabbit (1:200 dilution) secondary antibodies (Vector Laboratories, Burlingame CA) and HRP/DAB histochemistry (Sigma Fast 3.3 Diaminobenzidine Tablet Sets; Sigma, St. Louis, MO) were used to visualize the sites of labeling. Stained embryos were dehydrated in an ethanol series, mounted in methyl salicylate and Permount (Fisher Scientific, Pittsburgh PA), and analyzed via DIC optics using a Nikon Optiphot 2.

\section{Generation and analysis of a P[UAS-GFP::Morgue] transformant strain}

A GFP-Morgue DNA construct was generated using the pUAST vector (Brand and Perrimon 1993) by cloning the GFP coding region adjacent to the $\mathrm{NH}_{2}$-terminus of the Morgue coding region (amino acids 2-491). The fidelity of the construct was verified via DNA sequence analysis. pGFPMorgue plasmid DNA was purified via a QIAGEN plasmid maxi kit. Transformant flies were generated by the Duke University Model System Genomics Facility (Durham, NC). P[UAS-GFP:Morgue] insertions were mapped and balanced or homozygosed as appropriate to establish strains.

GFP fluorescence in animals carrying P[UAS-GFP:Morgue] and a $\mathrm{P}[\mathrm{Gal} 4]$ driver was analyzed using a Zeiss LSM 510 Meta Confocal System at the University of Massachusetts Central Microscopy Center (http://www.bio.umass.edu/microscopy/).

\section{Generation and analysis of pIZT-Morgue in cultured Sf9 cells}

A Morgue::His DNA construct where a $6 x$ His tag was added to the morgue open reading frame was generated via PCR. The Morgue::His DNA was cloned into the pIZT vector (Novagen, Madison, WI) and pMorgue::His plasmid DNA purified. Transient transfections were performed on cultured Lepidopteran Sf9 cells with the pMorgue::His plasmid as described previously (Wing et. al., 2002). Immunostaining of transfected Sf-9 cells was performed using a QIAexpress Anti-His HRP conjugase kit (QIAGEN, Valencia, CA). plZT-Morgue transfected Sf9 cells were washed with 1 XPBS and fixed in acetone:methanol (1:1) for 1 min. The fixed cells were washed with $1 \times P B S$ and then incubated with blocking buffer provided with the kit for at least 1 hour at $4^{\circ} \mathrm{C}$. The cells were washed with $1 \mathrm{xPBS}$, and incubated with Penta-His HRP conjugate antibody in $1 \mathrm{xPBS}$ at $4^{\circ} \mathrm{C}$ overnight. The cells were washed in $1 \mathrm{xPBS}$ and stained via HRP/DAB histochemical reactions, and visualized via DIC optics using a Nikon Optiphot 2.

\section{Acknowledgements}

The authors are grateful to Tanja Godenschwege and Ying Zhou for providing comments on the manuscript and Lindsay Wilson and Kelly Anne McKeown for experimental assistance. We thank John Reinitz, Jasprina Noordermeer, and the Developmental Studies Hybridoma Bank (University of lowa, IA) for providing antibodies, and Eric Spana and the Duke University Model System Genomics Facility for generation of transformant Drosophila. We also acknowledge the Bloomington Drosophila Stock Center (Indiana University, IN) for providing fly stocks. This work was supported by a grant from the National Institute for Aging at the $\mathrm{NIH}$.

\section{References}

ARAMA, E., AGAPITE, J., STELLER, H. (2003). Caspase activity and a specific cytochrome $\mathrm{C}$ are required for sperm differentiation in Drosophila. Dev Cell 4 : 687-697.

BARTKE, T., POHL, C., PYROWOLAKIS, G. JENTSCH, S. (2004). Dual role of BRUCE as an antiapoptotic IAP and a chimeric E2/E3 ubiquitin ligase. Mol Cell 14: 801-811.

BERGMANN, A., YANG, A.Y., SRIVASTAVA, M. (2003). Regulators of IAP function: coming to grips with the grim reaper. Curr Opin Cell Biol 15: 717-724.

BRAND, A.H., PERRIMON, N. (1993). Targeted gene expression as a means of altering cell fates and generating dominant phenotypes. Development 118: 401415.

CIECHANOVER, A. (2005). Intracellular protein degradation: from a vague idea through the lysosome and the ubiquitin-proteasome system and onto human diseases and drug targeting. Cell Death Differ 12: 1178-1190.

DENG, M., HOCHSTRASSER, M. (2006). Spatially regulated ubiquitin ligation by an ER/nuclear membrane ligase. Nature 443: 827-831.

DESMOTS, F., RUSSELL, H.R., LEE, Y., BOYD, K., MCKINNON, P.J. (2005). The reaper-binding protein scythe modulates apoptosis and proliferation during mammalian development. Mol Cell Biol 25: 10329-10337.

EDDINS, M.J., CARLILE, C.M., GOMEZ, K.M., PICKART, C.M., WOLBERGER, C. (2006). Mms2-Ubc13 covalently bound to ubiquitin reveals the structural basis of linkage-specific polyubiquitin chain formation. Nat Struct Mol Biol 13: 915920.

FU, J., JIN, Y., AREND, L.J. (2003). Smac3, a novel Smac/DIABLO splicing variant, attenuates the stability and apoptosis-inhibiting activity of X-linked inhibitor of apoptosis protein. J Biol Chem 278: 52660-52672.

GEISBRECHT, E.R., MONTELL, D.J. (2004). A role for Drosophila IAP1-mediated caspase inhibition in Rac-dependent cell migration. Cell 118: 111-125.

GESELLCHEN, V., KUTTENKEULER, D., STECKEL, M., PELTE, N., BOUTROS M. (2005). An RNA interference screen identifies Inhibitor of Apoptosis Protein 2 as a regulator of innate immune signalling in Drosophila. EMBO Rep 6: 979984.

GIOT, L., BADER, J.S., BROUWER, C., CHAUDHURI, A., KUANG, B., LI, Y., HAO, 
Y.L., OOI, C.E., GODWIN, B., VITOLS, E., VIJAYADAMODAR, G., POCHART, P., MACHINENI, H., WELSH, M., KONG, Y., ZERHUSEN, B., MALCOLM, R., VARRONE, Z., COLLIS, A., MINTO, M., BURGESS, S., MCDANIEL, L., STIMPSON, E., SPRIGGS, F., WILLIAMS, J., NEURATH, K., IOIME, N., AGEE, M., VOSS, E., FURTAK, K., RENZULLI, R., AANENSEN, N., CARROLLA, S., BICKELHAUPT, E., LAZOVATSKY, Y., DASILVA, A., ZHONG, J., STANYON, C.A., FINLEY, R.L. Jr, WHITE, K.P., BRAVERMAN, M., JARVIE, T., GOLD, S., LEACH, M., KNIGHT, J., SHIMKETS, RA., MCKENNA, M.P., CHANT, J., ROTHBERG, J.M. (2003). A protein interaction map of Drosophila melanogaster. Science 302: 1727-1736.

GRETHER, M.E., ABRAMS, J.M., AGAPITE, J., WHITE, K., STELLER, H. (1995). The head involution defective gene of Drosophila melanogaster functions in programmed cell death. Genes Dev 9: 1694-1708.

HAMILTON, M.H., TCHEREPANOVA, I., HUIBREGTSE, J.M., MCDONNELL, D.P. (2001). Nuclear import/export of hRPF1/Nedd4 regulates the ubiquitin-dependent degradation of its nuclear substrates. J Biol Chem 276: 26324-26331.

HAU, D.D., LEWIS, M.J., SALTIBUS, L.F., PASTUSHOK, L., XIAO, W., SPYRACOPOULOS, L. (2006). Structure and interactions of the ubiquitinconjugating enzyme variant human Uev1a: Implications for enzymatic synthesis of polyubiquitin chains. Biochem 45: 9866-9877.

HAUSER, H.P., BARDROFF, M., PYROWOLAKIS, G., JENTSCH, S. (1998). A giant ubiquitin-conjugating enzyme related to IAP apoptosis inhibitors. J Cell Biol 141: 1415-1422.

HAY, B.A. (2000). Understanding IAP function and regulation: a view from Drosophila. Cell Death Differ 7: 1045-1056.

HAYS, R., WICKLINE, L., CAGAN, R. (2002). Morgue mediates apoptosis in the Drosophila melanogaster retina by promoting degradation of DIAP1. Nat Cell Biol 4: 425-431.

HO, M.S., TSAI, P.I., CHIEN, C.T. (2006). F-box proteins: the key to protein degradation. J Biomed Sci 13: 181-91.

HOLLEY, C.L., OLSON, M.R., COLON-RAMOS, D.A., KORNBLUTH, S. (2002). Reaper eliminates IAP proteins through stimulated IAP degradation and generalized translational inhibition. Nat Cell Biol 4: 439-444.

HUH, J.R., FOE, I., MURO, I., CHEN, C.H., SEOL, J.H., YOO, S.J., GUO, M., PARK, J.M., HAY, B.A. (2007). The Drosophila IAP DIAP2 is dispensable for cell survival, required for the innate immune response to Gram-negative bacterial infection, and can be negatively regulated by the Reaper/Hid/Grim family of IAPbinding apoptosis inducers. J Biol Chem 282: 2056-2068.

HUH, J.R., VERNOOY, S.Y., YU, H., YAN, N., SHI, Y., GUO, M., HAY, B.A. (2004a). Multiple apoptotic caspase cascades are required in nonapoptotic roles for Drosophila spermatid individualization. PLoS Biol 2: E15.

HUH, J.R., GUO, M., HAY, B.A. (2004b). Compensatory proliferation induced by cell death in the Drosophila wing disc requires activity of the apical cell death caspase Dronc in a nonapoptotic role. Curr Biol 14: 1262-1266.

KLEINO, A., VALANNE, S., ULVILA, J., KALLIO, J., MYLLYMÄKI, H., ENWALD, H., STÖVEN, S., POIDEVIN, M., UEDA, R., HULTMARK, D., LEMAITRE, B., RÄMET, M. (2005). Inhibitor of apoptosis 2 and TAK1-binding protein are components of the Drosophila Imd pathway. EMBO J 24: 3423-3434.

KONDO, S., SENOO-MATSUDA, N., HIROMI, Y., MIURA, M. (2006). DRONC coordinates cell death and compensatory proliferation. Mol Cell Biol 26: 72587268.

KORNBLUTH, S., WHITE, K. (2005). Apoptosis in Drosophila: neither fish nor fowl (nor man, nor worm). J Cell Sci 118: 1779-1787.

LAI, C.H., CHOU, C.Y., CHANG, L.Y. (2000). Identification of novel human genes evolutionarily conserved in Caenorhabditis elegans by comparative proteonomics. Genome Res 10: 703-713.

LEE, J.C., PETER, M.E. (2003). Regulation of apoptosis by ubiquitination. Immunol Rev 193: 39-47.

LEULIER, F., LHOCINE, N., LEMAITRE, B., MEIER, P. (2006). The Drosophila inhibitor of apoptosis protein DIAP2 functions in innate immunity and is essential to resist gram-negative bacterial infection. Mol Cell Biol 26: 7821-7831.

LEULIER, F., VIDAL, S., SAIGO, K., UEDA, R., LEMAITRE, B. (2002). Inducible expression of double-stranded RNA reveals a role for dFADD in the regulation of the antibacterial response in Drosophila adults. Curr Biol 12: 996-1000.

LEWIS, M.J., SALTIBUS, L.F., HAU, D.D., XIAO, W. SPYRACOPOULOS, L. (2006). Structural basis for non-covalent interaction between ubiquitin and the ubiquitin conjugating enzyme variant human MMS2. J Biomol NMR 34: 89-100.

MACFARLANE, M., MERRISON, W., BRATTON, S.B., COHEN, G.M. (2002). Proteasome-mediated degradation of Smac during apoptosis: XIAP promotes Smac ubiquitination in vitro. J Biol Chem 277: 36611-36616.

MUKHERJEE, A., SHAN, X., MUTSUDDI, M., MA, Y., NAMBU, JR. (2000). The Drosophila sox gene, fish-hook, is required for postembryonic development. Dev Biol 217: 91-106.

MURAD, A., EMERY-LE, M., EMERY, P. (2007). A subset of dorsal neurons modulates circadian behavior and light responses in Drosophila. Neuron 53 : 689-701.

NOORDERMEER, J.N., KOPCZYNSKI, C.C., FETTER, R.D., BLAND, K.S., CHEN, W.Y., GOODMAN, C.S. (1998). Wrapper, a novel member of the Ig superfamily, is expressed by midline glia and is required for them to ensheath commissura axons in Drosophila. Neuron 21: 991-1001.

OLSON, M.R., HOLLEY, C.L., YOO, S.J., HUH, J.R., HAY, B.A., KORNBLUTH, S. (2003). Reaper is regulated by IAP-mediated ubiquitination. J Biol Chem 278:4028-4034.

OSHIMA, K., TAKEDA. M., KURANAGA, E., UEDA, R., AIGAKI, T., MIURA, M., HAYASHI, S. (2006). IKK epsilon regulates $F$ actin assembly and interacts with Drosophila IAP1 in cellular morphogenesis. Curr Biol 16: 1531-1537.

PATEL, N.H. (1994). Imaging neuronal subsets and other cell types in whole-mount Drosophila embryos and larvae using antibody probes. In: Drosophila melanogaster: practical uses in cell and molecular biology, methods in cell biology (Eds. L.S.B. Goldstein LSB, E.A. Fryberg), vol. 44. New York: Academic Press, pp 446-485.

PEREZ-GARIJO, A., MARTIN, F.A., MORATA, G. (2004). Caspase inhibition during apoptosis causes abnormal signalling and developmental aberrations in Drosophila. Development 131: 5591-5998.

PICKART, C.M., EDDINS, M.J. (2004). Ubiquitin: structures, functions, mechanisms. Biochim Biophys Acta 1695: 55-72.

RYOO, H.D., GORENC, T., STELLER, H. (2004). Apoptotic cells can induce compensatory cell proliferation through the JNK and the Wingless signaling pathways. Dev Cell 7: 491-501.

RYOO, H.D., BERGMANN, A., GONEN, H., CIECHANOVER, A., STELLER, H. (2002). Regulation of Drosophila IAP1 degradation and apoptosis by reaper and ubcD1. Nat Cell Biol 4: 432-438.

SCHREADER, B.A., WANG, Y., NAMBU, J.R. (2003). Drosophila morgue and the intersection between protein ubiquitination and programmed cell death. Apoptosis 8: 129-139.

SEVRIOUKOV, E.A., BURR, J., HUANG, E.W., ASSI, H.H., MONSERRATE, J.P PURVES, D.C., WU, J.N., SONG, E.J., BRACHMANN, CB. (2007). Drosophila $\mathrm{Bcl}-2$ proteins participate in stress-induced apoptosis, but are not required for normal development. Genesis 45: 184-193.

SEPP, K.J., SCHULTE, J., AULD, V.J. (2000). Developmental dynamics of peripheral glia in Drosophila melanogaster. Glia 30: 122-133.

SONNENFELD, M.J., JACOBS, J.R. (1995). Apoptosis of the midline glia during Drosophila embryogenesis: a correlation with axon contact. Development 121: 569-578

STELLER, H. (2008). Regulation of apoptosis in Drosophila. Cell Death Diff 15: 1132-1138.

STOVEN, S., SILVERMAN, N., JUNELL, A., HEDENGREN-OLCOTT, M., ERTURK, D., ENGSTROM, Y., MANIATIS, T., HULTMARK, D. (2003). Caspase-mediated processing of the Drosophila NF-kappaB factor Relish. Proc Natl Acad Sci USA 100: 5991-5996.

THRESS, K., HENZEL, W., SHILLINGLAW, W., KORNBLUTH, S. (1998). Scythe: a novel reaper-binding apoptotic regulator. EMBO J 17: 6135-6143.

UMESONO, Y., HIROMI, Y., HOTTA, Y. (2002). Context-dependent utilization of Notch activity in Drosophila glial determination. Development 129: 2391-2399.

VAUX, D.L., SILKE, J. (2005). IAPs - the ubiquitin connection. Cell Death Differ 12: 1205-1207.

VAUX, D.L., SILKE, J. (2003). Mammalian mitochondrial IAP binding proteins. Biochem Biophys Res Commun 304: 499-504.

VERNOOY, S.Y., CHOW, V., SU, J., VERBRUGGHE, K., YANG, J., COLE, S., OLSON, M.R., HAY, B.A. (2002). Drosophila Bruce can potently suppress Rprand Grim-dependent but not Hid-dependent cell death. Curr Biol 12: 1164-1168. 
WILKINSON, J.C., WILKINSON, A.S., SCOTT, F.L., CSOMOS, R.A., SALVESEN, G.S., DUCKETT, C.S. (2004). Neutralization of Smac/Diablo by inhibitors of apoptosis (IAPs). A caspase-independent mechanism for apoptotic inhibition. $J$ Biol Chem 279: 51082-51090.

WING, J.P., SCHREADER, B.A., YOKOKURA, T., WANG, Y., ANDREWS, P.S. HUSEINOVIC, N., DONG, C.K., OGDAHL, J.L., SCHWARTZ, L.M., WHITE, K., NAMBU, J.R. (2002). Drosophila Morgue is an F box/ubiquitin conjugase domain protein important for grim-reaper mediated apoptosis. Nat Cell Biol 4: 451-456.

WRIGHT, C.W., DUCKETT, C.S. (2005). Reawakening the cellular death program in neoplasia through the therapeutic blockade of IAP function. J Clin Invest 115: 2673-2678.

YANG, Q.H., DU, C. (2004). Smac/DIABLO selectively reduces the levels of C-IAP1 and c-IAP2 but not that of XIAP and livin in HeLa cells. J Biol Chem 279: 1696316970

YOO, S.J. (2005). Grim stimulates Diap1 poly-ubiquitination by binding to UbcD1. Mol Cells 20: 446-451.

YOO, S.J., HUH, J.R., MURO, I., YU, H., WANG, L., WANG, S.L., FELDMAN, R.M., CLEM, R.J., MULLER, H.A., HAY, B.A. (2002). Hid, Rpr and Grim negatively regulate DIAP1 levels through distinct mechanisms. Nat Cell Biol 4: 416-424.

ZHOU, Y., CARPENTER, Z.W., BRENNAN, G.T, NAMBU, J.R. (2009). The unique Morgue protein is conserved in a diverse but restricted set of invertebrates. Mol Biol Evol 10: 2245-2259.

ZHOU, L., HASHIMI, H., SCHWARTZ, L.M., NAMBU, J.R. (1995). Programmed cell death in the Drosophila central nervous system midline. Curr Biol 5: 784-790. 


\section{Further Related Reading, published previously in the Int. J. Dev. Biol.}

See our recent Special Issue Placenta edited by Joan S. Hunt and Kent L. Thornburg at: http://www.ijdb.ehu.es/web/contents.php?vol=54\&issue=2-3

Both jnk and apoptosis pathways regulate growth and terminalia rotation during Drosophila genital disc development Sergio Benitez, Claudia Sosa, Nicolás Tomasini and Ana Macías Int. J. Dev. Biol. (2010) 54: 643-653

Early neural cell death: numbers and cues from the developing neuroretina Ana I. Valenciano, Patricia Boya and Enrique J. de la Rosa Int. J. Dev. Biol. (2009) 53: 1515-1528

Apoptosis in Drosophila: compensatory proliferation and undead cells Francisco A. Martín, Ainhoa Peréz-Garijo and Ginés Morata Int. J. Dev. Biol. (2009) 53: 1341-1347

\section{Generation of pattern and form in the developing limb}

Matthew Towers and Cheryll Tickle

Int. J. Dev. Biol. (2009) 53: 805-812

Drosophila retinal pigment cell death is regulated in a position-dependent manner by a cell memory gene Nicolas Dos-Santos, Thomas Rubin, Fabienne Chalvet, Pierre Gandille, Frederic Cremazy, Jacqueline Leroy, E. Boissonneau and Laurent Théodore

Int. J. Dev. Biol. (2008) 52: 21-31

Metamorphosis of Hydractinia echinata (Cnidaria) is caspase-dependent Stefanie Seipp, Karola Wittig, Beate Stiening, Angelika Böttger and Thomas Leitz Int. J. Dev. Biol. (2006) 50: 63-70

\section{Mouse-chick neural chimeras}

Josiane Fontaine-Pérus and Yvonnick Chéraud

Int. J. Dev. Biol. (2005) 49: 349-353

A generalized caspase inhibitor disrupts early mammalian development Zahra Zakeri Richard A. Lockshin, Luis-Miguel Criado-Rodríguez and Carlos Martínez-A Int. J. Dev. Biol. (2005) 49: 43-51

Elucidating the molecular mechanisms that underlie the target control of motoneuron death. Glen B Banks and Peter G Noakes Int. J. Dev. Biol. (2002) 46: 551-558

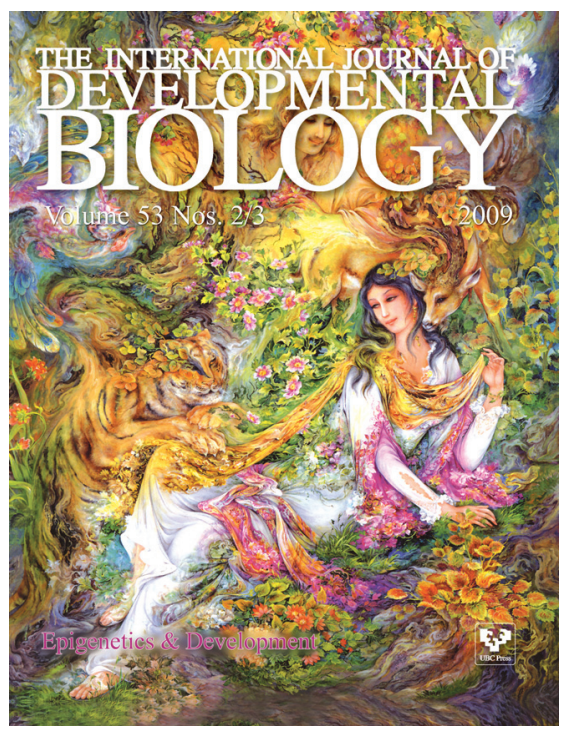

5 yr ISI Impact Factor $(2009)=3.253$

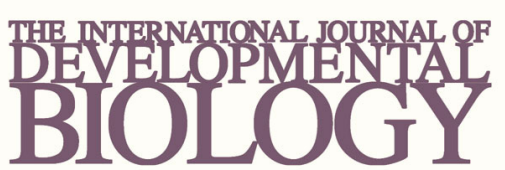

Volume 54 Nos. 6/7
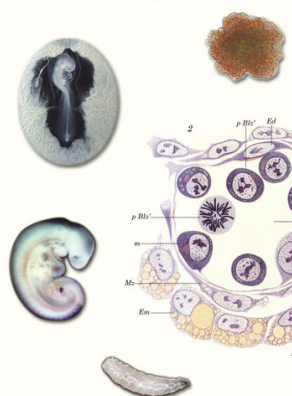

Special Issue

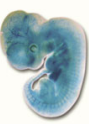

Developmental Hematopoiesis

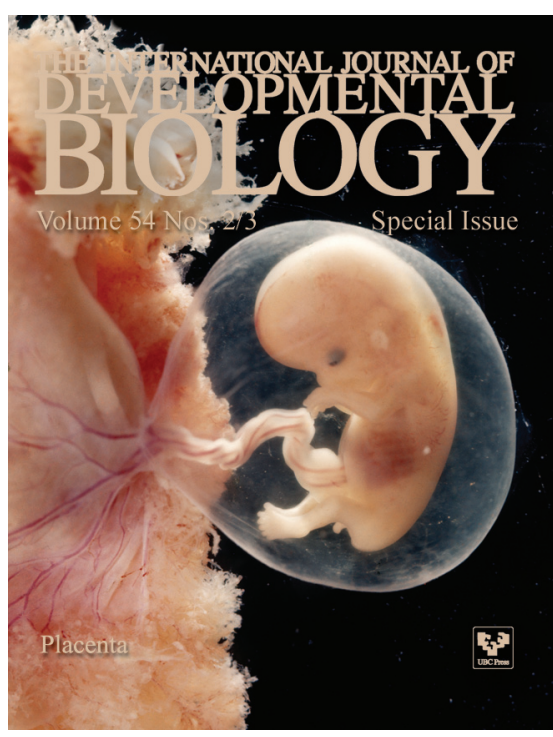

